\title{
O futuro do Hospital Nossa Senhora está em suas mãos
}

\section{The Future of Nossa Senhora hospital is in Your Hands}

Resumo: A gestão de um hospital filantrópico é mais complexa do que aparenta. Embora receba benefícios fiscais, sua gestão depende da tomada de decisões tal qual as empresas privadas. A organização em estudo, o Hospital Nossa Senhora, trata-se de uma instituição filantrópica, ou seja, sem fins lucrativos, idealizada por um grupo de indivíduos visionários, na década de 80 , que fundaram um hospital para melhor atender a comunidade. Porém, a manutenção dessa entidade tornou-se uma tarefa que exige muito dos gestores. Após ter passado por duas crises financeiras, o futuro do hospital é incerto e depende de uma série de decisões de seus gestores. Diante ao exposto, esse caso pretende promover uma discussão sobre a gestão das instituições sem fins lucrativos e sobre a dificuldade dos hospitais frente aos problemas de gestão pública e do Sistema Único de Saúde (SUS).

Palavras-chaves: Organizações sem fins lucrativos. Planejamento estratégico. Saúde pública. Terceiro setor.

Abstract: The management of a philanthropic hospital is more complex than it appears to be. Even though the hospital receives tax benefits, its management depends on decision-making just like private companies. The organization studied is a philanthropic institution, that is, a non-profit institution, created by a visionary group in the 80 's, which founded a hospital to better serve the community. However, the financial maintenance of the institution became a task that required a lot of managers. After going through two financial crises, the future of the hospital was depending on a decision-making: it could close its doors, be privatized or receive additional investment and expand the range of health services. This study seeks to discuss the management of non-profit institutions and the difficulty hospitals face due to the problems in public management and the problems in the public health system.

Keywords: Non-profit organizations, strategic planning, public health, third sector.

Texto completo em português: http://www.apgs.ufv.br Full text in Portuguese: http://www.apgs.ufv.br

\section{Andressa Centenaro}

Professora da Faculdade da Associação Brasiliense de Educação (FABE Marau)

Mestra, Faculdade Meridional IMED

http://lattes.cnpq.br/7772158021080637

orcid.org/0000-0003-0239-1001

centenaro.andressa@gmail.com

Angela Maria Ortolan Bonemberger

Professora da Faculdade Meridional IMED

Mestra, Faculdade Meridional IMED

http://lattes.cnpq.br/9389922523086019

orcid.org/0000-0002-0725-6952

angela.bonemberger@imed.edu.br

Tainara Sartori

Especialista em Saúde/Administradora da 15ª Coordenadoria Regional de Saúde

Mestra, Faculdade Meridional IMED

http://lattes.cnpq.br/0547898481919838

orcid.org/0000-0003-2202-599X

tai.s@hotmail.com

Julio Cesar Ferro de Guimarães

Professor Adjunto da Universidade Federal de Pelotas (UFPEL)

Doutor, Pontifícia Universidade Católica (PUC/RS)

http://lattes.cnpq.br/1360508130357781

http://orcid.org/0000-0003-3718-6075

juliocfguimaraes@yahoo.com.br

Texto completo em português: http://www.apgs.ufv.br Full text in Portuguese: http://www.apgs.ufv.br

\section{Introdução}

Administrar um hospital filantrópico não é uma tarefa fácil. Embora receba benefícios fiscais, sua gestão depende de habilidades e características empreendedoras assim como as empresas privadas. A instituição analisada, o Hospital Nossa Senhora, localiza-se em um município próximo a Passo Fundo RS, com uma população estimada em 40.000 habitantes. Trata-se de um hospital estabelecido em prédio próprio, com uma área total de $5.239 \mathrm{~m}^{2}$, contendo 130 leitos, cerca de 50 médicos e 200 funcionários. Toda estrutura é voltada em $60 \%$ para atendimento ao SUS, ou seja, o centro hospitalar é um polo regional em saúde pública. Atualmente, atende 20 municípios da $6^{\underline{a}}$ região de saúde no Rio Grande do Sul, abrangendo em torno de 117 mil habitantes.
O hospital realiza por mês, em média, 500 internações, 3.500 consultas de emergência, 2.000 atendimentos ambulatoriais e 2.000 exames de diagnóstico.

O Hospital Nossa Senhora constitui-se em uma unidade civil leiga, beneficente, com autonomia administrativa e financeira. Por ser uma associação filantrópica, sem fins lucrativos, emprega seu resultado na manutenção e conservação do prédio do hospital. Seus investimentos são aplicados na aquisição de equipamentos médico-hospitalares e no desenvolvimento de pesquisas. Seus diretores e conselheiros não recebem remuneração ou vantagens de qualquer espécie ou título. A aplicação dos valores e rendas do eventual resultado operacional e de todos os recursos destinados à entidade (seja de fonte federal, estadual, municipal ou privada) são, 
integralmente, aplicadas na manutenção e desenvolvimento dos objetivos institucionais.

Entretanto, é de conhecimento que os hospitais filantrópicos de todo o Brasil passam por uma série de problemas. O SUS, além de pagar muito abaixo do valor de mercado, faz os pagamentos com atraso. Assim, os rendimentos provenientes do SUS, que devem ser $60 \%$ da receita nos hospitais filantrópicos, servem apenas para a manutenção dos serviços básicos. Ou seja, não sobra dinheiro para investimentos e melhorias nos hospitais. Além disso, muitos hospitais filantrópicos são marcados pela má gestão de seus recursos, com decisões arriscadas, sem planejamento, sem análise de suas características internas e externas e das necessidades da população. A realidade do Hospital Nossa Senhora não é diferente. Após 40 anos de história, depois de passar por várias crises financeiras e institucionais, frente a uma nova administração, o hospital se vê diante de um dilema: continuar ou não a sua história?

O objetivo deste caso consiste em proporcionar a reflexão e promover a discussão sobre temas ligados a planejamento estratégico, tomada de decisão, comportamento organizacional e terceiro setor. A partir disso, é possível perceber e refletir sobre as decisões estratégicas que os gestores devem tomar em organizações filantrópicas ou privadas. Sugere-se a utilização deste caso nos cursos de graduação, nas disciplinas de teorias organizacionais, administração estratégica, planejamento estratégico, tomada de decisão, comportamento organizacional e terceiro setor.

\section{Um pouco de história}

O primeiro hospital do município em questão era uma Santa Casa de Misericórdia, administrado pelas Irmãs Franciscanas, o que era muito comum nos municípios do estado naquela época. Por volta de 1964, a Santa Casa foi adquirida por um grupo de médicos que criaram outro hospital, sendo este, uma instituição privada e com finalidade lucrativa. Em meados de 1980, um médico chegou na cidade para atuar nesta instituição, porém, por motivos políticos, foi impedido de exercer o ofício da medicina. O ocorrido provocou indignação e chamou a atenção de um grupo de empresários da cidade, principalmente, a do Sr. José Constantino Beneficente. Proprietário de uma das grandes empresas do município, ele sentiu que a população, seus filhos e netos não poderiam ficar sem um hospital que atendesse a comunidade, solidariamente, como as Santas Casas de Misericórdia. Assim, o Sr. José motivou um grupo de empresários e alguns outros médicos a criar, definitivamente, um novo hospital na cidade, porém, com caráter filantrópico, voltado a atender a comunidade e as pessoas mais carentes.

O Hospital Nossa Senhora, então, foi fundado em 20 de fevereiro de 1976, por meio de um movimento organizado por esse grupo de indivíduos, com a finalidade de conseguir fundos para construir a estrutura física do hospital. Entre as ações realizadas para sua construção, destacam-se os títulos de doações vendidos à população e alguns recursos angariados junto ao governo estadual. O objetivo desse grupo de indivíduos era fundar uma instituição com caráter filantrópico - o que levaria a instituição a ter benefícios fiscais e proporcionaria atendimento para a população como um todo. Atender a comunidade é uma prática enraizada na cultura do município e região.

Realizar ações em prol da comunidade, dos filhos e dos netos é uma característica de cidades interioranas, que honram e cultivam as tradições repassadas de geração em geração. Conforme Costa e Visconti (2001), o voluntariado no Brasil possui suas raízes no processo da colonização, quando as ações assistenciais foram assumidas por grupos ligados essencialmente à Igreja Católica. $\mathrm{O}$ ato de voluntariar, nesse sentido, forjado nas bases religiosas, encontrava-se aderente aos valores cristãos que pregavam o amor e a doação ao próximo como meio de aproximação com Deus.

Entre os anos 1976 e 1984, ocorreu a construção da estrutura física do hospital. O local escolhido para implantação do novo centro hospitalar foi um dos pontos mais altos da cidade. Nesse mesmo ínterim, acontecia na região a construção da Ferrovia do Trigo, na qual contava com máquinas, equipamentos (explosivos) e profissionais habilitados. Então, para facilitar as obras de detonação de pedras e a terraplanagem no alto do morro, foram contratados, junto à empresa que executava a construção da ferrovia, os serviços e os materiais necessários para dar início à construção física do prédio.

Em 1984, com o Hospital Nossa Senhora construído, o mesmo entrou em atividade e começou a realizar as primeiras consultas médicas. A primeira providência tomada pelos dirigentes do hospital foi credenciá-lo no Instituto Nacional de Assistência Médica da Previdência Social (INANPS) e no Fundo de Assistência ao Trabalhador Rural (FUNRURAL). À época, era o INANPS que atuava junto ao Ministério da Saúde e tinha a incumbência de promover a saúde e prevenir doenças. Criado em 1974, o INANPS também tinha a finalidade de prestar atendimento médico/dentário aos que contribuíam com a previdência social. Enquanto o FUNRURAL, instituído por meio de Lei Complementar em 1971 e subordinado ao Ministério do Trabalho e Previdência Social, executava o Programa de Assistência ao Trabalhador Rural em diversas áreas de benefícios, entre elas, a garantia de acesso aos serviços de saúde. A atitude de credenciar o hospital junto ao INANPS e ao FUNRURAL aumentou o número de consultas, possibilitando aos trabalhadores da zona rural e urbana o atendimento na rede de saúde pública.

Seguindo suas atividades e buscando, cada vez mais, atender seu caráter filantrópico, em 1990, o hospital deu início aos atendimentos efetuados via SUS. Para tanto, precisou aprovar uma série de documentos de filantropia no Conselho de Assistência Social, onde, por meio de grupos voluntários, recebeu a declaração das esferas federal e estadual como sendo um hospital de utilidade pública. Esta medida era uma de várias exigências legais para manutenção do título de entidade filantrópica. Sendo assim, no mínimo $60 \%$ dos atendimentos realizados no hospital deveriam ser efetuados pelo SUS.

Ainda no ano de 1990, o Sr. José Beneficente Neto, neto do Sr. José Constantino Beneficente, idealizador do Hospital Nossa Senhora, é eleito presidente do conselho diretor do Hospital Nossa 
Senhora. Muito feliz em continuar o legado do seu avô, o Sr. José Beneficente Neto não sabia o que viria pela frente e que o futuro do hospital estaria em suas mãos.

\section{As dificuldades surgem}

Ainda durante a década de 1990, por seu porte classificatório como instituição hospitalar de média complexidade, o hospital foi obrigado a atender quatro especialidades básicas em saúde (clínica geral, pediatria, ginecologia e obstetrícia) em regime de 24 horas. Entretanto, sua estrutura financeira não permitia manter os médicos atuantes dessas áreas de plantão. Começava assim, uma das primeiras dificuldades do Hospital Nossa Senhora.

Os problemas financeiros, relacionados à manutenção das quatro especialidades, afetou o atendimento de gestantes. Esse contexto, no ano de 1996, chamou a atenção do promotor público municipal que, por sua vez, mobilizou as principais lideranças em saúde do município; em reunião decidiram pressionar o poder público local para bancar o atendimento obstétrico. Como o atendimento à saúde é obrigatoriedade dos governos nas esferas municipal, estadual e federal, o município, que também tem o dever de manter $o$ atendimento nas quatro especialidades básicas, optou por conveniar com o hospital e bancar a assistência/atendimento obstétrico. Surgiu assim, o primeiro convênio com a prefeitura local. No convênio, estava previsto que a prefeitura pagasse o sobreaviso dos médicos obstétricos, enquanto o hospital ofereceria os serviços de enfermagem e a estrutura física para os atendimentos. A partir desse ato, outros municípios sem atendimento hospitalar passaram a conveniar com o Hospital Nossa Senhora, a fim de também usufruir do atendimento básico em saúde pública.

A década de 1990 foi de muitas realizações, contudo, de muitos problemas também. No ano de 1998, com o hospital em dificuldades financeiras e poucas opções de pessoas dispostas a geri-lo, o conselho decidiu que instituição passasse a ser administrada por um grupo privado. Neste ano, o Plano de Saúde Pronto-clínica assumiu a direção do centro hospitalar. Essa parceria permitiu ao grupo o gerenciamento dos atendimentos efetuados pelo SUS e também a ocupação da estrutura do hospital para atender os outros clientes do Plano de Saúde. A passagem dessa administração terceirizada protagonizou, inclusive, algumas reformas no hospital, como a expansão do laboratório e da sala de raio X. O convênio durou até o ano de 2004 , sendo que seu término foi ocasionado pelo fato de a Pronto-clínica mudar a estratégia de negócios, abandonando as administrações hospitalares e passando a atuar somente junto aos planos de saúde por ela mantidos.

Após término de convênio com a Pronto-clínica e sob nova direção, no ano de 2006, o hospital implantou o atendimento de urgência, emergência e o pronto atendimento. Ampliando o convênio junto a prefeitura, foi possível abrir espaço aos atendimentos 24 horas. Aliando a funcionalidade do pronto atendimento e o interesse do município em manter o atendimento de urgência e emergência, bem como o pronto atendimento 24 horas à disposição dos munícipes, o hospital passou a atender uma demanda externa, há muito tempo solicitada pela população.
Novamente, por meio de convênio, o município remunerava os serviços (médicos, enfermeiros e plantonistas) e a entidade entrava com o espaço físico e os equipamentos necessários. Sendo assim, foram utilizados aqueles espaços que estavam desativados, por exemplo, a antiga sala de raio $\mathrm{X}$ tornou-se pronto atendimento.

Observa-se que durante o período de 1984 a 2006, a atuação do hospital restringiu-se a sobreviver e manter a filantropia. Nesse processo, foi fundamental a participação de todos, especialmente, dos colaboradores e da diretoria, na pessoa do Sr. José Beneficente Neto, sempre interessados em dar continuidade aos serviços de saúde voltados à caridade e ao atendimento comunitário, como idealizado inicialmente pelo grupo de empresários fundadores do hospital. Foi um período crítico, de muita luta para sobreviver e muita luta para atender as necessidades da sociedade. Todas as ações realizadas pelo hospital iam de encontro ao que o ambiente determinava. Não haviam estratégias efetivas, havia sim, necessidades impostas pelos órgãos de saúde e pela demanda do momento. Foi um período de escolha mínima, onde a adaptação ocorria por meio da pressão externa, ou seja, a consolidação do hospital como instituição filantrópica dependia de um conjunto de iniciativas que pudessem atender às exigências do ambiente.

Sempre trabalhando com dificuldades de caixa, porém, buscando atender de forma adequada aos anseios da sociedade, o hospital, no ano de 2008, deparou-se com a possibilidade de ampliar seus leitos e sua história, podendo adquirir bens móveis postos à venda por seu então "concorrente", o hospital com fins lucrativos. Era um momento de glória social! Um hospital filantrópico tornar-se o único hospital do município, com chances de ampliar seus atendimentos e querendo tranquilizar os munícipes na questão de atender a todos, mesmo tornando-se único, era a prova cabal à sociedade de autossuficiência e controle. Mais que isso, a possibilidade de comprar parte dos bens do hospital mais antigo e preferido da cidade, com fama de bons atendimentos e voltado a atender quem detinha capital, deixou o então presidente do conselho diretor do Hospital Nossa Senhora, Sr. José Constantino, em um impasse... Qual seria a melhor decisão? O valor a ser investido era alto, $\mathrm{R} \$ 1,8$ milhões. Deveria ele tranquilizar a sociedade que estava aflita pela perda de um hospital e com medo de ficar sem atendimento, precisando talvez, buscar socorro em outras cidades? Deveria ele contrair empréstimo junto às instituições financeiras para adquirir os bens do outro hospital? Deveria o hospital de caridade ampliar seus objetivos e sua movimentação?

\section{A pior crise}

A decisão foi tomada sem um planejamento estratégico definido, sem avaliação de investimento e financiamento. A tomada de decisão foi determinada, mais uma vez, pela pressão do ambiente externo. Foram gastos $\mathrm{R} \$ 1,8$ milhões com a compra de bens móveis do outro hospital, aumentado a capacidade de leitos de 59 para 110. Contudo, pelo porte do município, os 60 leitos eram suficientes e, conforme relato de um dos gestores do centro hospitalar, o coordenador de projetos do Hospital Nossa Senhora, 
Sr. José Carlos, "quando da ocupação máxima do hospital em período de inverno, os 60 leitos existentes não chegavam à ocupação máxima". Sendo assim, expandir a capacidade de internação não parecia ser a melhor alternativa para uma instituição em crise financeira e precisando aumentar sua receita. Pelo contrário, a crise financeira que já era um problema, agravou-se! A situação passava a ser mais crítica do que antes! Contudo, outros problemas ainda estavam por vir...

Depois de adquirir equipamentos e mobiliários hospitalares, outra necessidade que não havia sido planejada surgiu: espaço físico para alocar os novos bens móveis, ou melhor, os antigos móveis do outro hospital. Dessa forma, no ano de 2009, o Sr. José Beneficente Neto e a diretoria do hospital resolveram aumentar o espaço físico do edifício e investiram $\mathrm{R} \$ 2.550 .000,00$ no projeto de ampliação. Entretanto, sem disponibilidade de caixa e em crise financeira, o Hospital Nossa Senhora financiou os valores em instituições financeiras locais no Curto Prazo (CP) e com altas taxas de juros para o mercado de investimentos. Novamente, sem planejamento de investimento e financiamento, os dirigentes do hospital tomaram decisões movidas pelo ambiente externo e pela necessidade interna. Conclusão essa, demonstrada no relato do coordenador de projetos da instituição:

"Como ficaria o atendimento da saúde na cidade? Dois hospitais pareciam insuficientes, um daria conta da demanda em atendimento médico e hospitalar para a região? Temendo uma indisposição da sociedade, a direção do hospital toma a decisão de aumentar o número de leitos existentes...".

Em um momento em que a maioria dos hospitais enxugavam os custos e buscavam investimentos que pudessem aumentar a receita, o Hospital Nossa Senhora investia, desnecessariamente, contraindo empréstimo de curto prazo, a altas taxas de juros... Com certeza, as decisões tomadas acalmaram os medos da sociedade quanto aos leitos disponíveis, entretanto, a entidade mergulhava, cada vez mais, em uma crise financeira!

Próximo a fechar suas portas, no ano de 2010, o hospital deparou-se com mais uma pressão externa: o sindicato da categoria de profissionais da saúde pressionava, terrivelmente, para que os hospitais reduzissem o número de horas semanais trabalhadas, exceto para os setores administrativos. Diante deste fato, a direção do hospital cedeu e reduziu de 40 para 36 horas semanais dos seus trabalhadores. Não foi uma decisão unânime entre os hospitais, mas foi uma decisão do hospital em estudo. Evidentemente, a atitude tomada gerou um profundo desconforto com os demais hospitais da região que, acertadamente, não procederam da mesma forma.

Mais uma decisão equivocada! O Hospital Nossa Senhora que já estava em crise passou a mergulhar em uma crise extrema! Reduzir a carga horária dos seus colaboradores gerou um déficit do atendimento e, portanto, fizeram-se necessárias novas contratações de colaboradores para suprir os horários faltantes. $O$ aumento da folha de pagamento mensal onerou em torno de $13 \% 0$ gasto mensal com recurso humano. Com a redução de horário dos funcionários, mais pessoas tiveram que ser integradas ao quadro técnico para compensar as quatro horas semanais reduzidas no acordo sindical. Resultado: para honrar seus compromissos de manutenção, sem capital de giro suficiente, necessariamente, mais empréstimos bancários foram contraídos! Logo, a crise financeira que já era grande, tornou-se ainda maior.

Dentre tantas crises financeiras enfrentadas pelo Hospital Nossa Senhora, sem dúvida, a vivida entre os anos de 2008 a 2011 foi a mais crítica e dramática! "Não havia luz no fim do túnel! ". Em seu período mais conturbado e crítico, a associação filantrópica demonstrava sinais de fragilidade e seu fechamento tornou-se iminente... A grave crise financeira levou o hospital para o mesmo caminho de seu antigo concorrente. Para a comunidade, colaboradores, funcionários, conselheiros e diretores pairava o medo da sucumbência... O hospital particular já havia fechado, e esse estava prestes. Diante os fatos, só um milagre o manteria de portas abertas!

Cabe lembrar ainda que a garantia dos empréstimos tomados pela direção do Hospital Nossa Senhora eram os bens pessoais de alguns diretores, inclusive, bens do Sr. José Beneficente Neto. Portanto, não era somente o pavor de fechamento que rondava a instituição, havia também o patrimônio particular dos seus mantenedores em risco.

Diante os fatos, o que fazer?

Devendo cerca $R \$ 6,7$ milhões a bancos locais, cujas taxas de juros beiravam $1,75 \%$ ao mês e, por consequência, comprometendo grande parte da disponibilidade de caixa com o pagamento de juros, - Sr. José Beneficente Neto decidiu mudar a estratégia. Concluiu que a melhor solução seria a profissionalização do Hospital Nossa Senhora e a troca de sua direção administrativa.

Para ocupar o cargo em destaque, de diretor administrativo, era necessário um profissional que, além de experiente, empreendedor e administrador, reunisse características de líder. Após algumas semanas, o novo diretor, Sr. Antônio Sérgio, tomou posse e assumiu a gestão do Hospital Nossa Senhora. As primeiras medidas do Sr. Antônio Sérgio buscaram a união entre os colaboradores e a renegociação das dívidas que assolavam a existência da entidade.

Com uma nova percepção administrativa, foi viabilizada uma linha de crédito junto ao Banco Nacional de Desenvolvimento Social (BNDES). O novo financiamento foi utilizado para quitar todas as dívidas de curto prazo (cujos juros atingiam uma média de 1,75\% a.m.). Sendo assim, o hospital substituía várias dívidas por uma única de longo prazo (120 meses) com taxas de juros muito mais baixas, cerca de 3,00\% a.a. Essa atitude promoveu o início de um processo de recuperação financeira. $\mathrm{O}$ fato de pagar menos juros de empréstimos, todo mês, propiciou um fôlego de caixa importante, considerando o momento de muitas dificuldades financeiras no hospital, conforme relatou o novo diretor do hospital, Sr. Antônio Sérgio:

"O primeiro item da reestruturação financeira foi a renegociação da dívida, que era de seis milhões e setecentos mil em dívida. Buscamos uma linha de crédito do BNDES Saúde. Nós tínhamos um desembolso de 275 mil reais por mês para pagar as dividas e os encargos, todo mês isso só aumentava. Nós reduzimos isso para 40 
à 50 mil reais por mês... Então, houve a redução do comprometimento financeiro e início do pagamento da dívida. Nós tínhamos dívidas com vários bancos, agora nós temos apenas com o BNDES, a um prazo de 10 anos com juros de $3 \%$ ao ano, mais a variação da TJLP."

Contudo, somente ganhar fôlego de caixa não era suficiente para o Hospital Nossa Senhora superar a crise, era preciso mais... O futuro do Hospital Nossa Senhora precisava ser pensado, era preciso garantir não somente sua sobrevivência, mas também sua continuidade, sustentabilidade e longevidade. Posto isso, nesse momento qual decisão seria a mais adequada a ser tomada pelo Sr. José Beneficente Neto, presidente do conselho diretor da instituição? O futuro do Hospital Nossa Senhora está em suas mãos.

\section{Sugestões de questionamentos para discussão e análise}

a) O Hospital Nossa Senhora possui uma história de 40 anos de caridade em prol da saúde pública, possuindo vários pontos fortes e oportunidades a serem exploradas, mas também alguns problemas tanto internos, quanto externos. A análise SWOT pode fornecer um mapeamento do contexto histórico e espacial em que as organizações atuam, tanto internamente quanto externamente. Executando essa análise na instituição, quais seriam seus pontos fortes, pontos fracos, ameaças e oportunidades? Quais seriam seus recursos e capacidades?

b) Em alguns momentos, a direção do hospital tomou decisões equivocadas? Quais e por quê?

c) Conforme a literatura sobre gestão de entidades filantrópicas, quanto maior a interação das organizações sem fins lucrativos com a comunidade melhores serão as formas de adaptação e subsistência garantida. Pelo fato do hospital ser uma instituição filantrópica, atuando $60 \%$ para atender a saúde pública, você acredita que seria possível abrandar a crise financeira com o envolvimento da comunidade e de empresas com interesse social? Como essa ideia poderia ser implementada? Quais as ações deviam ser desenvolvidas pelos gestores do hospital?

d) Sobre o aspecto estratégico, um dos problemas enfrentados pelos administradores das entidades filantrópicas encontra-se em planejar suas atividades de longo prazo. Isso porque a volatilidade dos recursos disponíveis dificulta o planejamento e o orçamento dessas entidades. Agora, o futuro do Hospital Nossa Senhora está em suas mãos, na condição de presidente do conselho diretor, qual seria sua decisão em relação ao futuro dele? 